\title{
O ensino da pesquisa científica orientada no curso técnico em Edificações
}

\author{
Carolina Bini \\ Juan Peres de Oliveira
}

Fátima Peres Zago de Oliveira

\section{Resumo}

Este artigo tem como objetivo discutir a integração da Pesquisa e Iniciação Científica no Curso Técnico em Edificações do Instituto Federal Catarinense - Campus Rio do Sul. A disciplina de Pesquisa Orientada em Edificações permite o diálogo entre teoria e prática projetual, que é trabalhada em conjunto durante um semestre. Nela, os alunos têm o contato com referenciais teóricos e podem escrever suas críticas em um artigo a ser entregue no final da disciplina, assim como desenvolvem o projeto de uma edificação de livre escolha, que é aprimorado também durante as aulas. Como resultado, busca-se encontrar a troca de informações entre teoria e prática, proporcionando ao aluno, formação técnica e também possibilidade de discussão teórica e justificativa de argumentos em relação às suas atividades futuras.

Palavras-chave: Iniciação Científica, Curso Técnico Profissionalizante, Teoria, Processo projetual. 


\title{
The teaching of scientific research oriented in the technical course in Buildings
}

\author{
Carolina Bini \\ Juan Peres de Oliveira \\ Fátima Peres Zago de Oliveira
}

\begin{abstract}
This paper aims to discuss the integration of Research and Scientific Initiation in the Technical Building Course of the Federal Institute Catarinense - Campus Rio do Sul. The discipline of Oriented Research in Buildings allows the dialogue between theory and design practice, which is worked together during a semester. In this subject, students have contact with theoretical references and can write their critiques in an article to be delivered at the end of the semester, as well as develop the design of a building of free choice, which is also improved during the classes. As a result, it seeks to find the exchange of information between theory and practice, providing to the student technical training and the possibility of theoretical discussion and justification of arguments related to their future activities.
\end{abstract}

Key-words: Scientific Initiation, Technical Course, Theory, Project Process. 


\section{Introdução}

A Iniciação Científica, atividade presente nos cursos de graduação tem grande importância no processo de tomada de decisões do aluno, aprimorando sua autoria, sua autonomia, e contribuindo para o aprofundamento do conhecimento. Nos cursos técnicos, e na educação básica, a pesquisa articulada com o estudo da teoria nem sempre é considerada prioridade nas disciplinas. Porém, para Oliveira (2017), estudos da Iniciação Científica no ensino médio confirmam que:

A Iniciação Científica proporciona a integração entre as áreas do conhecimento; entre a pesquisa, a teoria e a prática; e entre o ensino, a pesquisa e a extensão, o que torna o processo de aprendizagem mais dinâmico e que instiga a capacidade de enfrentar novas situações numa sociedade em constante mudança (OLIVEIRA, 2017, p.17).

Foi com o intuito de aplicar o estudo de teoria através da pesquisa que a disciplina de Pesquisa Orientada em Edificações se destacou no curso técnico de mesmo nome do Instituto Federal Catarinense - Campus Rio do Sul, tornando possível a discussão da integração entre Iniciação Científica e prática projetual com os alunos.

O trabalho da disciplina ao longo de um semestre culminou em um artigo explicando o processo projetual para construir uma edificação, que foi de livre escolha de cada estudante. Os alunos integraram a teoria e a prática projetual, considerando que cada uma delas complementa o processo de aprendizagem na área de edificações. Assim, foram estabelecidos itens de pesquisa em cada aula, partindo da concepção de estudos preliminares e finalizando com o projeto executivo.

O envolvimento dos alunos com a pesquisa se tornou interessante, já que foi necessário dedicação e atenção aos temas escolhidos e sequência de itens de pesquisa. A evolução de opiniões e pensamentos de cada aluno foi visível com o passar das aulas, desenvolvendo práticas antes desconhecidas pelos indivíduos, que em maioria tem nível médio completo como formação.

Diante desses argumentos, o objetivo deste estudo foi discutir a relação entre a prática de projeto e sua relação com a teoria, através da introdução da pesquisa científica como disciplina no Curso Técnico em Edificações realizado no Instituto Federal Catarinense - Campus Rio do Sul.

\section{A pesquisa orientada em edificações}

A disciplina intitulada Pesquisa Orientada em Edificações já sinaliza o conteúdo trabalhado durante os vinte encontros presenciais com os alunos: a pesquisa sobre temas relacionados à edificações. O termo "pesquisa" insinua a procura de teoria para explicar as 
escolhas projetuais de cada aluno e a "orientação" se encontra no auxílio dos profissionais da área de edificações, que contribuíram no processo de projeto dos alunos.

Nas primeiras aulas, depois que cada aluno escolheu seu tema de projeto, alguns assuntos foram descritos e apresentados, como: a sequência de projeto e suas metodologias de processo, estudos de caso e referências sobre temas específicos em arquitetura e engenharia e várias discussões que quebraram paradigmas e padrões, organizando o pensamento de cada um de outra maneira, já que é preciso pensar no mundo contemporâneo e não em repetição de modelos. Lerner (2013), político e arquiteto e urbanista, aponta que:

A diversidade é o que traz a riqueza da mistura, do complementar, do diverso. É expressa nas diferentes etnias, nas diferentes idades, nas diferentes rendas, nos diferentes usos, nas diferentes tipologias que animam o cenário urbano. Conecta-se a dois elementos fundamentais à qualidade de vida urbana: a identidade e a coexistência. (LERNER, 2013 p.3)

Assim, as primeiras aulas foram utilizadas para que os alunos escolhessem com cuidado o tema em que trabalharam durante o semestre, desenvolvendo por meio do exercício de projeto a parte teórica e prática de uma edificação, sintetizando como trabalho final da disciplina um artigo científico e um anteprojeto da edificação. A Tabela 1 explana os temas escolhidos pelos dezesseis alunos que cursaram a disciplina, identificando a diversidade de ideias encontradas na classe.

Tabela 1 - Tema de cada aluno da disciplina de Pesquisa Orientada em Edificações.

\begin{tabular}{l|l}
\hline Aluno & Tema escolhido para desenvolvimento de projeto \\
\hline 01 & Academia Cross Fit \\
\hline 02 & Biblioteca e Café \\
\hline 03 & Biblioteca Verde e Sala de Estudos Container \\
\hline 04 & Casa Autossustentável \\
\hline 05 & Casa Container \\
\hline 06 & Casa Modular \\
\hline 07 & Casa Sustentável \\
\hline 08 & Centro Social Infantil \\
\hline 09 & Chalé na Montanha \\
\hline 10 & Clube Recreativo \\
\hline 11 & Confeitaria com Espaço para Eventos \\
\hline 12 & Lavação de Motos e Bar \\
\hline 13 & Posto Policial \\
\hline 14 & Residência Acessível \\
\hline 15 & Revitalização de Praça Recreativa \\
\hline 16 & Sede Poliesportiva \\
\hline & Fonte: Elaborado pelos autores (2017). \\
\hline &
\end{tabular}


O método que se seguiu após a escolha do tema por cada aluno se deu através de três principais áreas de pesquisa e desenvolvimento de projeto, o Processo Projetual. Essas três principais áreas, de acordo com Castells (2012), são os produtos resultantes da atividade projetual e recebem as denominações de Estudo preliminar, Anteprojeto, Projeto ou ainda Projeto Executivo.

Além de integrar os componentes teóricos e práticos de projeto, essa disciplina permitiu relacionar conceitos de engenharia e arquitetura ao ambiente de pesquisa, estabelecendo aos alunos o aprendizado e transformação de suas ideias individuais em texto, com coerência e condição de boa leitura.

Foi por meio dessa linha de pensamento que os princípios das Novas Diretrizes Curriculares para a Educação Profissional Técnica se desenvolveram. A Resolução $n^{0}$ 6, de 20 de setembro de 2012, no Art. $14^{\circ}$ define que os currículos dos cursos devem proporcionar aos estudantes:

I - diálogo com diversos campos do trabalho, da ciência, da tecnologia e da cultura como referências fundamentais de sua formação; II - elementos para compreender e discutir as relações sociais de produção e de trabalho, bem como as especificidades históricas nas sociedades contemporâneas; III recursos para exercer sua profissão com competência, [...] bem como compromissos com a construção de uma sociedade democrática; IV domínio intelectual das tecnologias pertinentes ao eixo tecnológico do curso, de modo a permitir progressivo desenvolvimento profissional e capacidade de construir novos conhecimentos [...]; V - instrumentais de cada habilitação, por meio de vivência de diferentes situações práticas de estudo e de trabalho; VI - fundamentos de empreendedorismo, cooperativismo, tecnologia da informação, legislação trabalhista, ética profissional, gestão ambiental, segurança do trabalho, gestão da inovação e iniciação científica, gestão de pessoas e gestão da qualidade social e ambiental do trabalho (BRASIL, 2012).

\section{O Estudo Preliminar}

A primeira etapa que compõe a metodologia do processo de projeto é a mais conceitual e abstrata. É nela que o partido é sugerido, ou seja, a escolha de uma ideia começa a surgir. Para Castells (2012), o partido constitui a essência do projeto, e é o primeiro contato do aluno com a parte teórica projetual e também com a Iniciação Científica. A partir das primeiras pesquisas realizadas sobre o tema, os alunos já iniciaram a procura de informação por meio de referenciais teóricos, que direcionam suas opiniões sobre tal assunto.

Após o primeiro contato dos alunos com a pesquisa e referenciais teóricos, se apresentaram diferentes conceitos relacionados ao projeto, como conforto ambiental do ambiente construído, acessibilidade, mobilidade urbana, composição da forma e sistemas estruturais. Cada um desses itens foi discutido de acordo com o tema individual de cada estudante, já que se diferenciavam em questões de área, fluxos e formas de projeto. 
Informações referentes aos assuntos foram adicionadas ao artigo que cada um montava juntamente com o projeto que desenvolvia.

Ao mesmo tempo em que os alunos trabalhavam com a parte teórica, foi necessário desenvolver a prática projetual. Atividades como o diagnóstico do terreno, a legislação vigente, o zoneamento atual do município, o perfil do usuário, o programa de necessidades, e o pré-dimensionamento da edificação foram aprimorados na disciplina. Era necessário que as duas etapas, a teórica e a prática se desenvolvessem juntas.

\section{O Anteprojeto}

Após o desenvolvimento da primeira etapa, o processo seguiu para o anteprojeto, que é onde o aluno, depois de todo o diagnóstico de sua área, inicia o processo de desenho e ideias de forma da edificação. A relação entre volumetria e funcionalidade começa a ser pensada nessa etapa de projeto, assim como a distribuição e circulação.

Os alunos relacionam a parte teórica pesquisada e iniciaram a parte prática através de desenhos, identificando as informações pesquisadas em seu terreno e área de projeto. Foi hora de pensar na forma que a edificação proporcionava e desenvolver os ambientes funcionais do espaço, permitindo o uso das atividades antes realizadas, como perfil do usuário, programa de necessidades e pré-dimensionamento. Juntamente ao processo de projeto, os alunos criaram seus desenhos e explicaram em forma de texto o que estavam pensando para o projeto, desenvolvendo assim o artigo.

O dimensionamento do projeto é o ponto mais importante neste momento para o trabalho de cada estudante. Foi nesse ponto do projeto que eles calcularam e encaixaram todos os ambientes do programa de necessidades na forma final desejada. De acordo com Neufert (1976), referência em dimensionamento de objetos e ambientes, "deve-se conhecer as dimensões dos espaços mínimos que o homem utiliza diariamente, [...] visto que a sua compreensão contribui para criar uma noção correta de escala e auxiliar a encontrar as dimensões convenientes para muitos casos" (NEUFERT, 1976, p.18).

A partir do dimensionamento efetuado, aconteceu o exercício de zoneamento, onde o aluno definiu a localização de cada ambiente em seu projeto, propondo consequentemente soluções para questões de insolação e ventilação, sistemas estruturais, circulação e fluxos. Como momento final desta etapa, o aluno deve ter em mãos o desenho de sua edificação prédefinido, ou seja, deve existir o esboço de uma planta baixa auto explicativa, onde se possa entender todos os conceitos trabalhados na disciplina até aquele momento e deixar para a próxima etapa o momento de modelagem definitiva do projeto, onde se encontram os desenhos digitais, seções planas e tridimensionais da edificação. 


\section{O Projeto}

Nesta última etapa do trabalho, o projeto foi concretizado. Todos os conceitos vistos até o momento foram discutidos e definidos, para que o projeto final fosse decidido. As soluções em relação à forma, volumetria e funcionalidade da edificação foram definidas, para dar continuidade aos desenhos que representaram a ideia que cada aluno obteve no início da disciplina.

Os desenhos aqui empregados são distinguidos entre técnicos e artísticos. Ching (2013) estabelece como análise gráfica a visão geral dos elementos, sistemas e organizações básicas que compõe uma obra. Os elementos se inter-relacionam para formarem um todo integrado. São aspectos fundamentais para uma edificação:

I - Sistema Espacial: integração tridimensional dos elementos e espaços que acomodam funções múltiplas na casa; II - Sistema Estrutural: vigas e lajes se apoiam numa malha de colunas; III - Sistema de Delimitação: quatro planos de paredes externas definem o volume retangular; IV - Sistema de Circulação: a escada e a rampa ligam os níveis (CHING, 2013, p.34).

Na parte técnica, se encontraram as plantas baixas, cortes e fachadas do projeto, e os desenhos artísticos foram compostos por modelos tridimensionais digitais ou físicos da proposta de projeto.

\section{Desenho Técnico}

O desenho técnico é considerado a forma de leitura de projetos idealizados pelos projetistas de edificações. A compreensão e execução dos desenhos é primordial para correta representação de seções planas. Para Xavier (2012), o desenho se manifesta como um código para uma linguagem, estabelecida entre o projetista e o leitor do projeto, envolvendo um certo nível de treinamento no seu entendimento.

Foi a partir do desenho técnico que os alunos representaram suas soluções finais para a edificação em questão. Os estudantes já tinham o conhecimento de disciplinas que ensinaram a programar desenhos por recursos computacionais, deixando-os aptos para representar suas ideias de forma bidimensional e tridimensional.

A sequência apresentada aos alunos dizia respeito à alguns desenhos que deveriam ser apresentados ao final do trabalho. Foram esses: a planta de situação da edificação, que identifica onde o terreno está em relação ao seu entorno na cidade; a planta de localização do terreno, que dá ênfase ao entorno imediato e localização de vias; a implantação, que demonstra a posição da edificação em relação ao terreno, assim como seus recuos e respeito à legislação, além de relacionar a edificação com sua cobertura; depois das plantas introdutórias são identificadas as plantas baixas, que variam de acordo com os níveis ISSN 2526-2882 
verticais do projeto de cada estudante, e por consequências os cortes transversais e longitudinais, que devem dar ênfase às áreas molhadas da edificação e às circulações verticais do volume. Após a demonstração interna, são destacadas as fachadas, que também seguem de acordo com a volumetria de cada um.

Na disciplina Pesquisa Orientada em Edificações, os alunos trabalhavam em seus desenhos durante o horário de aula e eram assessorados pelo professor quando existiam dúvidas em relação ao projeto. Em paralelo à execução dos desenhos, os alunos podiam pesquisar sobre tal assunto e continuar escrevendo suas críticas e observações no artigo trabalhado também em sala de aula.

Após a finalização dos desenhos bidimensionais, os estudantes optaram por trabalhar a forma e volumetria de sua edificação através de modelos tridimensionais, que se encaixavam nos desenhos artísticos acima mencionados, ou por meio de maquetes físicas, que dependiam da relação do aluno com trabalhos manuais.

\section{Desenho Artístico}

A parte artística do projeto se relaciona com a forma tridimensional do objeto e a questão de texturas e volumes que a edificação receberá. Para Mario Segall (2007), professor da Faculdade de Arquitetura e Urbanismo Mackenzie:

O projeto precisa de vários meios de expressão e representação para ser gerenciado. No caso da modelagem tridimensional, o horizonte se amplia. O ser humano pode ver o objeto de muitas formas a partir de seu repertório inicial. [...] Ele tem a possibilidade de escolher as perspectivas e passear pelo objeto, em uma experiência externa, real (SEGALL, 2007).

É a partir desse pensamento sobre perspectivas da forma que existe a necessidade de os alunos trabalharem com modelos tridimensionais e volumetria, para eles mesmos entenderem o que estão criando em relação às suas edificações e descobrirem que são permitidas várias possibilidades de se trabalhar uma forma, além de discutir que a fachada ou volumetria não é apenas a consequência da planta baixa criada anteriormente.

Depois de resolver a questão volumétrica, os alunos são levados à discussão sobre as duas formas de desenho, técnica e artística, desenvolvendo em seu artigo a compreensão sobre como elaborar a representação gráfica de cada projeto e a relação de modelagem em duas e três dimensões.

\section{A Apresentação Final}

O último passo no projeto dos alunos, já com os desenhos finalizados, foi a montagem de pranchas de apresentação, para uma amostra final. Além das pranchas, cada 
aluno deveria apresentar seu artigo e relacionar seu aprendizado em relação à integração da parte teórica e prática da disciplina.

Tal apresentação foi pensada para melhorar a arguição de cada aluno, pois em um curso de nível técnico, nem todos os indivíduos tiveram a oportunidade de aprofundar sua argumentação e discussão em determinados assuntos. Para que isso acontecesse de forma agradável, várias discussões foram feitas durante o semestre da disciplina, para incentivar os alunos a conversar e defender suas ideias.

Assim, depois dos desenhos concluídos e modelagem tridimensional realizada, os alunos terminaram as pranchas para a apresentação e o artigo. Se separou um dia de aula apenas para as apresentações e uma banca foi formada para avaliar os trabalhos de cada um. Além do professor da disciplina, outro professor que auxiliou os trabalhos foi convidado para a banca, assim como a coordenadora do curso técnico.

No dia das apresentações, cada aluno ganhou quinze minutos para apresentar seu projeto e seu artigo, e as bancas foram conduzidas pelos três professores, que ao final de cada apresentação comentavam sobre os trabalhos e sobre a evolução de cada um. Os colegas de turma também comentavam e elogiavam os projetos de cada um. Dessa forma, os alunos tiveram a experiência de apresentar um trabalho e defender suas ideias para colegas e professores.

\section{Resultados}

O produto deste artigo mostrou de forma clara a evolução de alunos no último semestre do Curso Técnico em Edificações. O curso, que teve a duração de dois anos, permitiu aos dezesseis indivíduos, a formação técnica para gerir, projetar e contruir obras com área máxima de $8 \mathrm{om}^{2}$ (oitenta metros quadrados).

Inserida entre as mais de vinte disciplinas que os alunos cursaram durante os quatro semestres, a disciplina de Pesquisa Orientada em Edificações proporcionou o conhecimento de metodologia de pesquisa e de etapas de um processo de projeto, possibilitando ao aluno o pensamento crítico e desenvolvimento de opiniões, tanto de ideias como de decisões projetuais.

Ao longo do semestre, os alunos evoluíram de forma positiva, desenvolvendo ao mesmo tempo os desenhos que mostravam suas ideias e a explicação textual que permitia o aperfeiçoamento da escrita para este nível de aprendizado.

Foi possível perceber a evolução tanto de representação de ideias, quanto de crítica à soluções, concluindo em uma apresentação admirável no final do semestre. Os professores se surpreenderam com a capacidade crítica e criativa dos alunos, e entenderam que a pesquisa e a teoria tiveram papel imprecindível nesta evolução. 


\section{Considerações finais}

A partir das considerações redigidas no artigo, foi possível perceber que a Iniciação Científica trabalhada na disciplina de Pesquisa Orientada em Edificações teve resultados positivos ao trabalhar a teoria com os alunos de nível técnico profissionalizante. O pouco contato dos estudantes com a pesquisa e teoria foi ampliada através dos exercícios realizados na disciplina durante o último semestre do curso, apresentando a possibilidade de integrar a parte teórica com a parte prática de projeto.

Os alunos entenderam a importância de pesquisar antes de desenvolver suas ideias, procurando referências teóricas que existiam na linha de pesquisa que dizia respeito à seu tema de projeto. As observações e diagnóstico realizados como estudos preliminares ajudaram a entender a relação da edificação com seu entorno, assim como os estudos de caso, que foram os responsáveis por gerar crítica dos alunos.

Nas outras etapas, que se relacionaram com a representação gráfica e funcionalidade do projeto, a dificuldade surgiu em relação à redação e explicação de ideias que cada aluno possuía para si. A crítica se mostrou consistente nos artigos e demonstrou capacidade de leitura e interpretação por parte dos alunos.

Entendeu-se que é possível trabalhar em pouco tempo de curso o nível teórico de projeto, proporcionando uma boa base de conhecimento aos alunos, que posteriormente formados, se relacionarão com outros profissionais de áreas diversas e poderão justificar suas decisões por meio de referências, direcionando sua posição com certeza do que estão fazendo e dando margem para a ampliação do conhecimento através de novas formações a serem realizadas.

Para outros trabalhos, sugere-se que a teoria e a prática sejam relacionadas em outras disciplinas do ensino técnico profissionalizante, procurando os pontos positivos e negativos das atividades ao longo de um semestre e observando a evolução dos alunos em relação à pesquisa, discussão e crítica de diversos temas que podem gerar reflexão.

\section{Referências}

BRASIL. Resolução CNE/CEB 6/2012. Diretrizes Curriculares Nacionais da Educação Profissional de Nível Médio. [Diário Oficial da União], Brasília, 21 de setembro de 2012, Seção 1, p.22.

CASTELlS, Eduardo. Traços e Palavras: sobre o processo projetual em Arquitetura. 1. ed. Florianópolis: Editora UFSC, 2012. 182p, il.

CHING, Francis D. K. Arquitetura: Forma, espaço e ordem. 3. ed. São Paulo: Bookman, 2013. 456p, il.

ISSN 2526-2882 
GEHL, Jan. Cidade Para Pessoas. 1. ed. São Paulo: Perspectiva, 2013. 262p. il.

NEUFERT, Ernst. Arte de projetar em arquitetura: princípios, normas e prescrições sobre construção, instalações, distribuição e programa de necessidades, dimensões de edifícios, locais e utensílios. 21. ed. São Paulo: Gustavo Gili do Brasil, 1976. 431p.il.

OLIVEIRA, Fátima Peres Zago. Pactos e Impactos da Iniciação Científica na Formação dos Estudantes do Ensino Médio. 2017. 343 f. Tese (Doutorado). Universidade Federal de Santa Catarina, Centro de Ciências Físicas e Matemáticas, Florianópolis, 2017.

SEGALL, Mario Lesar. Modelagem tridimensional real e ensino de arquitetura ferramenta de projeto e construção de repertório. Disponível em: < http://www.vitru vius.com.br/revistas/read/arquitextos/o8.091/186> Acesso em: 20 mai. 2017.

XAVIER, Sinval. Desenho Arquitetônico. 2012. 74p. Dissertação (Mestrado). Universidade Federal do Rio Grande, Escola de Engenharia, 2012.

\section{Biografia Resumida}

Carolina Bini: UFSC, Universidade Federal de Santa Catarina Programa de Pós-Graduação de Arquitetura e Urbanismo. Campus Reitor João David Ferreira Lima, s/n - Trindade. 88040-900 - Florianópolis - Santa Catarina

e-mail: arqcarolinabini@gmail.com

Juan Peres de Oliveira: FURB, Fundação Universidade de Blumenau - Graduação em Engenharia Civil. Campus 2, Rua São Paulo, 3250 - Itoupava Seca. 89030-o8o - Blumenau Santa Catarina

e-mail: juanperes2_72@hotmail.com

Fátima Peres Zago de Oliveira: IFC, Instituto Federal Catarinense Sede Urbana, Rua Abraham Lincoln, 210 - Jardim América 89160-202 - Rio do Sul - Santa Catarina.

e-mail: fatima@ifc-riodosul.edu.br 